\title{
Coupling of mechanics and transport in discrete meso-level model: model verification
}

\author{
Jan Mašek* and Jan Eliáśs \\ * Institute of Structural Mechanics \\ Brno University of Technology \\ Veveří 95, 60200 Brno, Czech Republic \\ e-mail: jan.masek1@vut.cz, jan.elias@vut.cz
}

\begin{abstract}
Cracking in concrete has a paramount impact on the durability of structures. The natural permeability of a healthy material is severely magnified in presence of cracks. Cracks form a network of channels capable to transport a fluid that may chemically or physically interact with concrete constituents or the reinforcing steel, leading to deterioration of structural members or whole structures. Moreover, the presence of a pressurized fluid in cracks and pores leads to further crack development and therefore also to further increase in permeability. In order to predict the behavior of fractured quasibrittle solids filled with a pressurized fluid, a robust mechanical model is needed to describe the crack widths, connectivity, tortuosity, spacing, etc. The mechanical model must be fully coupled with a transport model into a multiphysical solver. We present such a solver, developed according to [1], and validate it by comparison with experimental data from literature. The model is discrete, allowing to easily embody cracks and the coupling mechanisms. Individual discrete units represents mineral aggregates while the inter-particle contacts account for matrix between them.

The first verification concerns a water permeability test conducted in [2] by Wang. A water flow through a pre-cracked Brazilian disc specimen is measured in dependence on opening of cracks scattered throughout the specimen. Secondly, corrosion induced cracking is modeled as experimentally done by Mullard [3]. The resulting crack patterns are also compared against the results from numerical simulations in [4]. The results of comparison show a good prediction ability of the developed coupled discrete mesoscale model.
\end{abstract}

\section{REFERENCES}

[1] J. E. Bolander and S. Berton, "Simulation of shrinkage induced cracking in cement composite overlays," Cement and Concrete Composites, vol. 26, no. 7, pp. 861-871, 2004.

[2] K. Wang, D. C. Jansen, S. P. Shah, and A. F. Karr, "Permeability study of cracked concrete," Cement and concrete research, vol. 27, no. 3, pp. 381-393, 1997.

[3] J. A. Mullard and M. G. Stewart, "Corrosion-induced cover cracking of rc structures: New experimental data and predictive models," 2009.

[4] C. Fahy, S. J. Wheeler, D. Gallipoli, and P. Grassl, "Corrosion induced cracking modelled by a coupled transport-structural approach," Cement and Concrete Research, vol. 94, pp. 24$35,2017$. 